\title{
CORRELATES OF EARLY READING AND WRITING PERFORMANCE IN FILIPINO OF PREFIRST GRADE PUPILS
}

\author{
${ }^{1}$ Ava Ann P. Semorlan \& ${ }^{2}$ Adrian P. Semorlan \\ ${ }^{1}$ School of Saint Anthony, Philippines \\ ${ }^{2}$ Western Mindanao State University, Philippines \\ (avaannsemorlan@yahoo.com)
}

\begin{abstract}
The study aimed to determine the relationship between the reading and writing performance in Filipino of pre-first grade children and to explore the variables that relate to their reading and writing performance. The subjects were pre-first grade children whose ages ranged from five to seven years old and their parents. To identify the reading stages and writing performance that the children were operating in, reading and writing tests were administered. The study revealed that in reading, the majority of the children were operating in the story reading stage; while in writing most of them were operating in the phonetic spelling stage. The findings also showed the following: 1) there was a strong positive relationship between the reading and writing performance of the pre-first grade children; 2) IQ level had a slight positive relationship with their reading performance.; 3) IQ and some years in preschool had a moderate positive relationship with their writing performance, and; 4) age of first exposure to storybooks had a moderate negative relationship with reading and writing performance. This study showed that the reading and writing stages of the pre-first grade children operate in are strongly related. This means that children who can read can likewise write in the language that they can read. This finding also supports the Cognitive theory that explains how reading and writing grow and develop simultaneously. The theory explains how reading becomes very similar to the act of writing since reading is a process of building mental meanings from textual clues. Recommendations base on the findings of this study: a) Reading and writing in the early years should be taught simultaneously; b) Preschool children should be exposed to story reading both in school and at home; c) story reading should be a basic part of the preschool program; d) Parents should be encouraged to support their children's early reading and writing experiences.
\end{abstract}

Keywords: Reading, Writing, Pre-first Grade, Cognitive theory 


\section{Introduction}

Many years back, children started their formal education in the elementary years. This notion was modified time when Froebel advocated Kindergarten. According to Morrison (2002), educating children as a group in a special place outside the home was important. His ideas have been so accepted throughout the world, and until now it is widely introduced with changes. Nowadays, education has welcomed the toddler, kinder and prep levels that encompass the "preschool education." Children need to pass in preschool education first before entering the elementary grade.

Reading and writing activities are incorporated in every aspect of the children's daily classroom experiences (Hildebrand, 1997). Beginning reading and writing of early literacy development are severals phases of learning through which children develop in different ways and tempos. It is a complex process that occurs between ages five through eight (Ramsburg, 1998).

According to the National Association for the education of children (NAEYS, 1998), Vygotsky (1962) and Boaten (1982), children develop both reading and writing competency from participating in significant literacy events such as storybook reading. One explanation may be that children's storybook experience is often adult-mediated, featuring modelling and direct instruction in language use (Cazden, 1992).

The Variations of children's reading and writing abilities in the prefirst grade level are influenced by certain factors that may be from home, school or the child's cognitive development. Thus, the researcher found interest in investigating the determinants of early reading and writing performances of pre-first-grade children.

\section{Problem Statement}

The purpose of the study was to determine the relationship between Early Reading and Writing stages of Pre-first grade children.

1. What stages are manifested in the reading and writing performance of pre-first grade pupils?

2. What is the relationship between the measure of intelligence (IQ) and early reading stages?

3. Does IQ level influence the writing stages of Pre-first grade children? 
4. Is there a significant positive relationship between the number of years in early education and early reading stages?

5. Does the number of years in early education positively correlate with early writing stages?

6. What is the relationship between the number of hours of adult's supervision and early reading stages?

7. Is a strong positive relationship evident between the number of hours of adult's supervision and early writing stages?

8. Is there a significant relationship between early exposure to storybooks and reading performance?

9. Does the age of first exposure to storybooks influence the writing stages of Pre-first grade children?

10. Is there a strong positive relationship between reading and writing stages of Pre-first grade children?

11. What are the prediction of the pupil's reading and writing stages?

\section{Methodology}

The researcher used the descriptive design. The survey research design was used in gathering data for the independent variables in the study. Responses of the Prep pupils' parents on the number of years that their children have had in early education, the number of hours taught by parents at home, and age first exposed to storybooks were gathered through questionnaires. Data on the prep pupils' IQ levels were derived from the guidance office.

\section{Participants of the Study}

The participants of the study were the whole morning population of 80 prefirst grade pupils with ages ranging from five to seven years old from School of Saint Anthony and their parents. There were 42 boys and 38 girls with a mean age of 6.28 .

\section{Research Instruments}

The research instruments consisted of questionnaires for the parents, 40 items reading test and a 30 item writing test. The questionnaires for parents aimed to gather data on the number of years their children went through in early education, number of hours supervised by parents at home and age when first exposed to storybooks. 
To determine which reading stage each pupil operates on, a 40-item reading test as administered. The test is composed of four categories, each with ten items. The categories include a reading of syllables, words, sentences and stories. The items on the test were chosen carefully to identify the child's reading stage.

Reading stages:

Stage 1- The child can sound 1-2 letters.

Stage 2- The child can read syllables/words.

Stage 3- The child can read syllables, words and understand sentences.

Stage 4 - The child can comprehend sentences and stories.

To determine the writing stage of the pupils, on the other hand, the pupils answered test on writing the beginning sound; writing the first two letters, and writing the names of the given pictures. Each pupil was also given a piece of paper to write a story.

Stage 1- (Letter Making Stage)-The child has the knowledge of letters and specific sounds.

Stage 2-(Beginning Phonetic)-The child can blend two sounds.

Stage 3 (Phonetic Speller)-The child can spell words correctly.

Stage 4 (Transitional Speller)-The child started using capital letters and punctuation marks correctly.

\section{Data Gathering Procedure}

Questionnaires for parents were stapled in the communication notebooks of the prep pupils to be answered by their parents. IQ results, on the other hand, were sourced from the Guidance office. The guidance counsellors administered the Otis-Lennon School Ability Test to determine the IQ level of the pupils.

On the first day, the teacher administered a 40 item reading test. The next day, the teacher administered a 30 item writing test. On the third day, pupils were given a piece of paper for them to write their stories.

\section{Data Analysis}

Frequency/Percentage, mean and standard deviation were the statistical tools for the study. 
The correlation was used to determine the relationship between the independent variables and the reading and writing stages.

\section{Results and Discussion}

\section{IQ Level and Reading Stages}

The Pearson correlation coefficient of the IQ level and reading stages mean is .281. This finding shows that the IQ significantly influences a child's reading ability. This is by Adam's (1990) findings in considering IQ level as one of the factors not strongly related to reading potential. Educators and parents will then provide the necessary materials and procedures to apply in enhancing the reading and writing abilities of their children.

\section{IQ level and Writing Stages}

The computed value of Pearson correlation coefficient for the mean scores on the exams for the writing stages and IQ level yielded an $r$ of .329. This result reveals a positive, moderate and significant relationship between IQ level and writing stages. This suggests that IQ level may serve as a potential variable towards a child's writing performance. Some pupils who obtained high IQ levels tend to do better in writing.

\section{Number of Years in Early Education and Means Scores of Exams for Reading Stages}

Having a computed Pearson correlation relationship of .337, it shows a moderate, positive and significant relationship between some years in early education and reading stages. This implies that the number of years the child went through in early education significantly influences a child's reading ability.

Preschool experience numerous activities before they attempt reading a book. This allows them to engage in the construction of meaning. Hildebrand (1997) noted that from infancy onwards, children are exposed to certain events which require organising of ideas enabling them to make sense of whatever they encounter. Thus, it depends on the child before entering the school on how he can deal with the construction of meaning about different texts encountered. At the same time, before early education experiences, early 
development in learning is more important in preparing a child to read (Goodman, 1985).

Moreover, Rousseau (cited by Brascombe, 2000) noted that learning takes place if a child finds in necessary. Therefore, regardless the number of years in early education experienced by the child, the child will learn to read once he realised its purpose. In this connection, Dodge and Bisckart (1998) stressed that children learn more when they observe adults read and write for certain reasons and when they find a reason to communicate.

\section{Number of Years in Early Education and Writing Stages}

The computed Pearson Correlation coefficient is .290. This implies that there is a significant and positive linear correlation between the number of years in early education writing stages. This indicates how the length of prior education enhances the writing performance of a child.

The more years the child has gone through early education, the higher stage in writing will he achieve. Pupils who have gone through the nursery and kinder levels can write words and stories. With the $24 \%$ of the subjects who can write stories, $23 \%$ have been into two years of previous education. Of the $7 \%$ on the other hand, who had difficulty blending sounds, $6 \%$ went through only a year of preschool education. The many writing activities pupils went through in their years in preschool education paved the way for the improvement of their writing ability. This emphasises that the length of experience in early education develops writing among prep pupils.

Also, Piaget (1986, cited by Maggart, 1992) stressed that experience is essential in developing the readiness of the child for school activities to be encountered.

The process of reading and writing is developed from the many experiences which start in the preschool years. Harris (1986), Adams (1990), Biscart (1998), and Gutieres (1980) noted preschool experiences as powerful factors in shaping the readiness of the child regarding reading and writing. Writing exercises likewise, reduce errors in writing. The importance of early education shows how prior preschool experiences contribute to the positive academic performance of a child.

In this regard, Burns and Griffin (1998) noted that early childhood program is necessary for helping children move toward acquiring necessary skills. All these things are to be experienced by a child in an early education program. 


\section{Length of Adults' Supervision and Reading Stages}

A Pearson $\mathrm{r}$ of .114 is computed which reveals a weak, positive, and not significant linear correlation between Length of Adults' supervision and Reading Stages, suggesting that learning to read is not based on how long an adult supervises his/her child.

The length of hours in teaching the child at home does not influence the reading and writing performance of a child. The manner on how parents teach their children is important to consider. Lessons imparted should be done in a pleasant manner to motivate the child to learn some more.

\section{Length of Adults' Supervision and Writing Stages}

The Pearson $r$ value of .108 is computed. This finding implies a weak, positive and non-significant relationship between the length of hours of adults' supervision and writing stages. This indicates that a child's writing ability is not influenced by the number of hours spent by adults in teaching their kids at home.

Studies noted the importance of adults' assistance towards cognitive development. However, it is important to consider the good feelings of the learning period. According to Essa (1992), any experience that develops good feelings about self-contributes to the potential of emerging reading and writing skills. Montessori (cited by Brascombe, 2000) further discussed "period of sensitivity" corresponding to a certain age. Learning exists when child's interest and mental capacity are suited to acquire knowledge.

\section{Age First Exposed to Storybooks and Reading Stages}

A Pearson correlation coefficient value of -.437 is computed. This result reveals a moderate, significant and negative relationship between the age first exposed to storybooks and reading stages. This emphasises that when a child is exposed to storybooks in later years, his reading performance less likely improves. In this regard, if children are exposed to storybooks at an early age, then the child tends to read better.

\section{Age First Exposed to Storybooks and Writing Stages}

The Pearson correlation coefficient computed is -,436. This finding reveals a negative, moderate and significant relationship between the age first exposed 
to storybooks and writing stages. This emphasises that pupils perform poorly in writing when exposed to storybooks later than two years old. Thus, exposure to storybooks at an early age means better writing performance for the child.

Maggart (1992) and Ruddell (1994) noted that reading and writing in the preschool years are enhanced by literate environments. This will build children's opportunities to create, fantasise, and explore ideas and language through the many school activities that may include play, extensive reading, and sharing of stories and books with children mediated by adults. Studies of Health (1982), Wells (1985), and Fietelson (1986) showed how valuable storybooks are in developing the literacy skills of children.

\section{Reading and Writing Stages}

A Pearson correlation of r-value of .902 is computed indicating a strong significant positive relationship between reading and writing stages. This implied those children who do better in reading likewise perform well in writing. Sulzby and Taele (1986) suggests that emergent reading and writing are closely interrelated. Both skills entail the knowledge of letters and sounds. The connection of both skills is for the purpose of communication. This finding supports the Cognitive theory which explains how reading and writing grow and develop simultaneously (Piaget, cited by Maggart, 1992.

\section{Conclusions}

Based on the results computed, the study revealed that Most pre-first grade pupils are story readers and transitional spellers (spell words correctly). IQ level significantly influences the child's reading ability. IQ level significantly influences the prep children's writing performance. There is a moderate positive relationship between the number of years in early education and early reading stages. The number of years in early education positively correlates with early writing stages. There is a weak, positive and non-significant linear correlation between the length of adults' supervision and reading and writing stages. There is a moderate, significant and negative relationship between the age of first exposure to storybooks and early reading stages. The age of first exposure to storybooks influences the writing performance of the child. There is a strong, significant and positive relationship between early reading and writing stages. Reading and writing develop simultaneously. Therefore, if a child is good in reading, then a higher chance is expected that he is good in 
writing. The age exposed to storybooks, and IQ level of pupils are predictors towards pupils' reading and writing stages. This implies that these variables affect the reading and writing stages of pupils.

\section{References}

Adams, A. (1990). Beginning to read: Thinking and learning about print. Cambridge Massachusetts: Institute of Technology Press.

Boaten, R. An analysis of the reading difficulties of grade one pupils in Sagada District, Mt. Province Division, Baguio Central University, Baguio City, RI, Philippines, MA Ed., 1980.

Brascombe, A. et al. (2000). Early childhood education. A constructivist perspective. New York: Houghton Muffin Company.

Cazden, C. (1992). Adult assistance to language development. New York: Teachers College Press.

Dodge, D. \& Bisckart, T. (1998). What every parent needs to know about preschool. USA: Sourcebooks, Inc.

Ersa, E. (1992). An early childhood curriculum. Canada. Delmar.

Fietelson D., Kita, B. \& Goldstein, Z. (1986). Effects of listening to series stories on first graders' comprehension and use of Language. Research in the Teaching of English, 20. 339-356.

Goodman, Y. (1985). "Kidwatching: Observing children in the classroom." In Observing the Language Learner, ed Angela Jaggar and M. Tricka SmithBurke, 9-18.

Gutierrez, N. Mga karaniwang kamalian sa mga sulating pormal ng mga mag-aaral sa Ika-anim na baiting sa ikatlong distrito,Mayila. The National Teachers' College, NCR, Philippines, 1980.

Harris L. \& Smith C. (1986). Reading instruction. USA: Mac Millan.

Heath, S.B. (1982). What no bedtime Stories means: Narrative skills at home and school. Language in Society, II, 49-56.

Hildebrand, V. (1997). An introduction of early education, $6^{\text {th }}$ ed. New Jersey: Viacom.

Maggart (1992). The reading process: The teacher and the learner. WMC Brown Communications Inc.

Morrison, G. (2000). Fundamentals of early education. New Jersey. Viacom.

National Education for the Education of Young Children (NAEYS), 1988. Learning to read and write: Developmentally appropriate practices for young children. Young Children, 53 (4), 30-46. 
Ramsburg (April 1998). Understanding Development in Young Parent News. National Parent Information Network. http://npin.Org/pnews/1998/pnew498b.html.

Ruddell,R. Et al. (1994). Theoretical models and processes of reading (4th ed). New York: International Reading Association.

Vygotsky, L.S. (1978) Mind in society. The development of higher psychological processes. Cambridge, MA: Harvard University Press. 